\title{
UTJECAJ UZGOJA KUKURUZA (Zea mays L.), SOJE (Glycine max. L.) I ULJANE REPICE (Brassica napus L.) NA ELEKTRIČNU PROVODLJIVOST I REAKCIJU TLA
}

THE INFLUENCE OF MAIZE (Zea mays L.), SOYBEAN (Glycine max. L.) AND OILSEED RAPE (Brassica napus L.) CULTIVATION ON ELECTRICAL CONDUCTIVITY AND SOIL REACTION

\author{
A. Špoljar, Ivka Kvaternjak, D. Žibrin, Mirjana Mužić
}

\section{SAŽETAK}

Tijekom 2018. godine na pokušalištu Visokog gospodarskog učilišta u Križevcima istraživan je utjecaj uzgoja kukuruza (Zea mays L.), soje (Glycine max. L.) i uljane repice (Brassica napus L.) na reakciju (pH u vodi i $1 \mathrm{MKCl-u}$ ) i električnu provodljivost (EC) tla. Istraživanja su provedena na hipogleju mineralnom nekarbonatnom ilovaste teksture. U tri su navrata tijekom vegetacije iz golog tla (crni ugar) i neposredno uz korijenov sustav biljaka uzeti prosječni uzorci od 0 do $30 \mathrm{~cm}$ i od 30 do $60 \mathrm{~cm}$ dubine. Iz njih je u laboratoriju određena $\mathrm{pH}$ vrijednost $\mathrm{u}$ vodi i $1 \mathrm{MKCl}-\mathrm{u}$ te električna provodljivost tla. Utvrđeno je da istraživane kulture zakiseljavaju tlo, a pri tome najveći učinak ima uljana repica. Kod nje su na obje dubine tla zabilježene uglavnom najmanje vrijednosti $\mathrm{pH}$ mjerenog u vodi i $1 \mathrm{MKCl}-\mathrm{u}$ te najmanje vrijednosti električne provodljivosti tla. Kod zadnjeg uzorkovanja u odnosu na početno stanje na svim su varijantama do $30 \mathrm{~cm}$ dubine tla utvrđene veće vrijednosti reakcije tla i uglavnom manje vrijednosti električne provodljivosti, što može biti rezultat pretežno vlažnog razdoblja u odnosu na suho tijekom vegetacije.

Ključne riječi: EC i pH tla, kukuruz, soja, uljana repica

\section{ABSTRACT}

During 2018, the influence of maize (Zea mays L.), soybean (Glycine max. L.) and oilseed rape (Brassica napus L.) cultivation on the reaction ( $\mathrm{pH}$ in water and $1 \mathrm{MKCl}$ ) and electrical conductivity (EC) in the soil was investigated at the experimental site of the Agriculture College in Križevci. Investigations were carried out on gleysoil of loamy texture. Average samples of soil at $0-30 \mathrm{~cm}$ and $30-60 \mathrm{~cm}$ depth were taken on three occasions during vegetation from black 
A. Špoljar i sur.: Utjecaj uzgoja kukuruza (Zea mays L.), soje (Glycine max. L.) i uljane repice (Brassica napus L.) na električnu provodljivost i reakciju tla

fallow and in close vicinity of the plant root system. In them, the $\mathrm{pH}$ value in the water and $1 \mathrm{MKCl}$ and the electrical conductivity in the soil were determined. It has been found that the studied crops acidify the soil, and the biggest effect is of oilseed rape. The lowest values of $\mathrm{pH}$ measured in water and $1 \mathrm{MKCl}$ and the lowest value of electrical conductivity of the soil were recorded for oilseed rape at both depths of the soil. At the end of the study, in all variants at $0-30 \mathrm{~cm}$ depth, generally higher values of soil reaction and mainly lower values of electrical conductivity were found, compared to the beginning of the research. The mentioned could be the result of a mostly humid period relative to dry period during vegetation.

Key words: EC and soil $\mathrm{pH}$, maize, soybean, oilseed rape

\section{UVOD I CILJEVI ISTRAŽIVANJA}

Poznato je kako korijenov sustav biljaka pri primanju kationa u otopinu tla, radi postizanja električne ravnoteže, izlučuje ione vodika pri čemu se tlo zakiseljava (Seguin i sur., 2004.; Vukadinović, 2011.). Međutim, iz dostupne literature može se zaključiti kako nije dovoljno istražen utjecaj pojedinih kultura na zakiseljavanje tla. Uglavnom se navodi njihova rezistentnost na različite uvjete kiselosti i električne provodljivosti tla. Tako su na primjer $\mathrm{pH}$ vrijednosti, kako navode Williams i sur. (2005.), manje od 5,2 vrlo štetne za rast i razvoj soje. Kritične $\mathrm{pH}$ vrijednosti, ovisno o tipu tla pri uzgoju kukuruza, prema navodima Abdulaha-Al Baquy i sur. (2018.) su između 4,46 i 5,07, a pri uzgoju uljane repice ove vrijednosti kreću se između 4,87 i 5,65 (Abdulaha-Al Baquy i sur., 2017.).

Autori se, isto tako, pretežno bave utjecajem povećanih koncentracija soli u tlu na uzgoj pojedinih kultura. Tako Francois (1994.) (cit. Franzen, 2007.) navodi kako je uljana repica tolerantna kultura na povećane EC vrijednosti. Hassan i sur. (1970.) izdvajaju kukuruz kao osjetljivu kulturu naspram povećanih EC vrijednosti u tlu, a Bernstein i Ogata (1966.) navode da je soja srednje tolerantna kultura na povećane koncentracije soli u tlu.

Kamkar i sur. (2014.) istražuju utjecaj prekomjerne zaslanjenosti i povećanih $\mathrm{pH}$ vrijednosti tla na uzgoj soje i uljane repice u plodoredu. Utvrđene $\mathrm{pH}$ vrijednosti na istraživanom području bile su između 7,5 i 7,8 i nisu ograničavajući čimbenik pri uzgoju ovih kultura. Nasuprot tomu, vrijednosti električne provodljivosti tla bile su veće od praga tolerancije koji je za uljanu 
A. Špoljar i sur.: Utjecaj uzgoja kukuruza (Zea mays L.), soje (Glycine max. L.) i uljane repice (Brassica napus L.) na električnu provodljivost i reakciju tla

repicu $11 \mathrm{dSm}^{-1}$ i $5 \mathrm{dSm}^{-1}$ za soju. Nešto manji prag tolerancije na povećane koncentracije soli u tlu kod uzgoja uljane repice prema drugim literaturnim navodima iznosi 9,5 $\mathrm{dSm}^{-1}$ (https://extension.usu.edu/publications/publication SO-03.pdf.). Kod ove vrijednosti elektroprovodljivosti tla prinos zrna uljane repice može biti manji do $50 \%$. Istraživanja utjecaja reakcije tla $\mathrm{i} / \mathrm{ili}$ njegove električne provodljivosti na uzgoj pojedinih kultura provode i drugi autori (Fox, 1979.; Ashraf i McNelly, 1990.; Bahizire, 2007.; Franzen, 2007.; Agarwal i sur., 2015. i dr.).

Autori, također, istražuju utjecaj provedenih mjera gospodarenja na neke značajke tla. Špoljar (2008.) u istraživanju utjecaja uzgoja usjeva u plodoredu te provedene kombinirane organske i mineralne gnojidbe s kalcifikacijom dobiva najveće prosječno smanjenje $\mathrm{pH}$ vrijednosti tla u $1 \mathrm{MKCl}-\mathrm{u}(\mathrm{za} 0,37)$ nakon berbe kukuruza, a najveće prosječno povećanje zabilježeno je pri uzgoju djetelinsko travne smjese (za 0,76). Azimzadeh i sur. (2015.) u istraživanju utjecaja zelene gnojidbe na prinos suhe tvari u zrnu kukuruza i uljane repice te na pojedine kemijske značajke tla utvrđuju povećanje električne provodljivosti za $35 \%$, dok se $\mathrm{pH}$ vrijednost tla smanjila za 0,3 . Da koncentracija pojedinih iona u tlu utječe na $\mathrm{pH}$ i EC vrijednosti ukazuju Liang i sur. (2016.). Autori navode kako manje koncentracije iona magnezija, natrija, sumpora i klora $\mathrm{u}$ području rizosfere utječu na smanjenje električne provodljivosti i $\mathrm{pH}$ vrijednosti tla. Nawaz i sur. (2012.) pri uzgoju riže isto tako u području rizosfere utvrđuju manje vrijednosti $\mathrm{pH}$ i elektroprovodljivosti tla u odnosu na prostor izvan korijenovog sustava.

Iz pregleda literature je vidljivo, kako se autori većinom bave utjecajem reakcije i električne provodljivosti tla na uzgoj pojedinih kultura ili utjecajem provedenih mjera gospodarenja na reakciju i električnu provodljivost tla. Zbog toga je na pokušalištu Visokog gospodarskog učilišta u Križevcima u tijeku 2018. godine istraživan utjecaj uzgoja kukuruza (Zea mays L.), soje (Glycine max. L.) i uljane repice (Brassica napus L.) na reakciju (pH u vodi i $1 \mathrm{M} \mathrm{KCl-u)}$ i električnu provodljivost (EC) tla.

\section{METODE I MATERIJALI ISTRAŽIVANJA}

Istraživanja su provedena na proizvodnoj površini veličine 7,5 ha na hipogleju mineralnom nekarbonatnom ilovaste teksture (Špoljar, 2008.). Metode istraživanja odgovaraju međunarodno prihvaćenim standardima pedoloških istraživanja (Pernar i sur., 2013.). U osam su ponavljanja u tri 
A. Špoljar i sur.: Utjecaj uzgoja kukuruza (Zea mays L.), soje (Glycine max. L.) i uljane repice (Brassica napus L.) na električnu provodljivost i reakciju tla

navrata tijekom vegetacije iz golog tla (crni ugar) i neposredno uz korijenov sustav biljaka uzeti prosječni uzorci tla od 0 do $30 \mathrm{~cm}$ i od 30 do $60 \mathrm{~cm}$ dubine. Uzorci su uzeti na početku, u sredini i na kraju vegetacije po fazama razvoja biljaka (Tablica 1.). Iz njih je u laboratoriju određena $\mathrm{pH}$ vrijednost u vodi i 1 MKCl-u (ISO 10390:2005) te električna provodljivost (EC) u uzorku tla i vode omjera 1: 5 (ISO 11265:2004).

Tablica 1. Vrijeme uzorkovanja tla

Table 1 Soil sampling time

\begin{tabular}{|c|c|c|}
\hline Kultura/Crop & $\begin{array}{c}\text { Faza razvoja/ } \\
\text { The development phase }\end{array}$ & $\begin{array}{l}\text { Datum uzorkovanja/ } \\
\text { Sampling date }\end{array}$ \\
\hline \multirow{3}{*}{$\begin{array}{l}\text { Uljana repica/ } \\
\text { Oilseed rape }\end{array}$} & $\begin{array}{l}\text { Početak cvatnje/ } \\
\text { The begining of flowering }\end{array}$ & 18. travnja/April 18 \\
\hline & $\begin{array}{l}\text { Formiranje komuške/ } \\
\text { Forming a commuter }\end{array}$ & 11. svibnja/May 11 \\
\hline & Zrioba/Maturation & 21. lipnja/June 21 \\
\hline \multirow{3}{*}{$\begin{array}{l}\text { Soja/ } \\
\text { Soybean }\end{array}$} & Grananje (tri do četiri grane)/Branching & 30. svibnja/May 30 \\
\hline & Cvatnja/Flowering & 2. srpnja/July 2 \\
\hline & Zrioba/Maturation & 14. rujna/September 14 \\
\hline \multirow{3}{*}{$\begin{array}{l}\text { Kukuruz/ } \\
\text { Maize }\end{array}$} & $\begin{array}{c}\text { Vegetativni porast (6-7 listova)/ } \\
\text { Vegetative growth }\end{array}$ & 30. svibnja/May 30 \\
\hline & Metličanje/Tasseling & 24. srpnja/July 24 \\
\hline & Zrioba/Maturation & 27. rujna/September 27 \\
\hline
\end{tabular}

Rezultati istraživanja statistički su obrađeni analizom varijance (ANOVA), a srednje vrijednosti testirane su LSD testom. Za statističku obradu podataka korišten je programski paket Statistica 12.1. (StafSoft, Inc. 2012).

\section{REZULTATI ISTRAŽIVANJA I RASPRAVA}

\section{Klimatski uvjeti}

Grafikon 1. prikazuje hod srednjih mjesečnih temperatura zraka i količine oborine za istraživanu 2018. godinu prema Walteru. Srednja godišnja temperatura zraka iznosila je $12,2{ }^{\circ} \mathrm{C}$, a godišnja količina oborine $873 \mathrm{~mm}$. U tijeku vegetacijskog razdoblja, kako je iz grafikona 1 . vidljivo, zabilježena su dva sušna razdoblja, jedno kraće, sredinom travnja, i jedno duže u kolovozu i rujnu. Međutim, uočljivo je da je vlažno razdoblje bilo dugotrajnije i trajalo je od početka svibnja do kraja srpnja. 
A. Špoljar i sur.: Utjecaj uzgoja kukuruza (Zea mays L.), soje (Glycine max. L.) i uljane repice (Brassica napus L.) na električnu provodljivost i reakciju tla

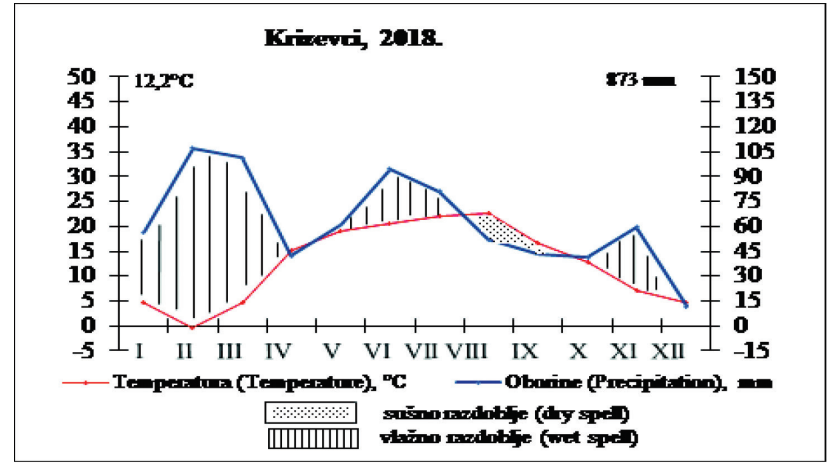

Grafikon 1. Klima dijagram prema Walteru za 2018. godinu

Graph 1 Climatic diagram according to Walter for the year 2018.

Kod svih je varijanata na kraju istraživanja na obje dubine tla u odnosu na početno stanje uglavnom utvrđeno povećanje $\mathrm{pH}$ vrijednosti tla mjerenog u vodi $\mathrm{i}$ $1 \mathrm{MKCl}-\mathrm{u}$ te smanjenje električne provodljivosti tla do $30 \mathrm{~cm}$ dubine. Međutim, utvrđene su manje $\mathrm{pH}$ vrijednosti tla za obje dubine kod svih istraživanih kultura u odnosu na golo tlo, pa se može reći da je korijenov sustav zakiseljava tlo. Utvrđene $\mathrm{pH}$ vrijednosti tla mogu biti rezultat pretežno vlažnog razdoblja $\mathrm{u}$ odnosu na suho i zbog toga manjeg sadržaja soli u tlu, što se odrazilo i na izmjerene $\mathrm{pH}$ vrijednosti u vodi i 1 MKCl-u. Rengel (2002.) također navodi kako se tijekom vlažnijeg razdoblja smanjuje koncentracija soli u tlu, a $\mathrm{pH}$ vrijednost tla se povećava. Tang i Rengel (2003.) (cit. Rengel 2015.) ističu kako se to ne odnosi na dugogodišnji utjecaj povećanih količina oborina zbog kojih se ispiru bazni kationi iz površinskog dijela tla i ono se postupno zakiseljava, nego je riječ o razmatranom vlažnijem razdoblju tijekom vegetacije.

Rezultati utjecaja uzgajanih kultura na reakciju i električnu provodljivost tla

U tablici 2. prikazani su rezultati utjecaja uzgajanih kultura na reakciju i električnu provodljivost tla po mjerenjima. Kod prvog mjerenja u obje dubine tla utvrđene su statistički opravdano manje vrijednosti $\mathrm{pH}$ mjerenog $\mathrm{u}$ vodi pri uzgoju svih kultura u odnosu na golo tlo (crni ugar). Također je utvrđena statistički opravdano manja $\mathrm{pH}$ vrijednost mjerena u vodi pri uzgoju uljane repice $u$ odnosu na kukuruz i soju, a između kukuruza i soje statistički opravdanih razlika nije bilo. Isto tako su utvrđene, pri drugom mjerenju, manje $\mathrm{pH}$ vrijednosti mjerene $\mathrm{u}$ vodi pri uzgoju uljane repice i soje $\mathrm{u}$ obje dubine $\mathrm{u}$ odnosu na golo tlo, a kod uzgoja kukuruza te su vrijednosti bile veće u odnosu na ostale istraživane varijante. Kod trećeg mjerenja $\mathrm{pH}$ vrijednosti tla u obje 
A. Špoljar i sur.: Utjecaj uzgoja kukuruza (Zea mays L.), soje (Glycine max. L.) i uljane repice (Brassica napus L.) na električnu provodljivost i reakciju tla

dubine pri uzgoju sve tri kulture bile su manje u odnosu na golo tlo. Statistički opravdano manje vrijednosti $\mathrm{pH}$ mjerenog u vodi na kraju vegetacije bile su pri uzgoju uljane repice u odnosu na ostale istraživane varijante.

Slični rezultati po mjerenjima dobiveni su i kod pH mjerenog u $1 \mathrm{MKCl}-\mathrm{u}$. Najmanja pH vrijednost mjerena u 1 MKCl-u zabilježena je pri uzgoju uljane repice. Na kraju istraživanja ova vrijednost bila je opravdano manja u odnosu na golo tlo, soju i kukuruz. Između soje, kukuruza i golog tla statistički opravdane razlike nisu utvrđene. Tijekom vegetacije većinom je zabilježen porast $\mathrm{pH}$ vrijednosti tla, što može biti rezultat prevladavanja vlažnog razdoblja u odnosu na suho tijekom vegetacije i manje koncentracije soli u vodenoj otopini tla do $30 \mathrm{~cm}$ dubine. Pri uzgoju uljane repice kod sva tri mjerenja utvrđene su manje vrijednosti električne provodljivosti tla u odnosu na golo tlo, kukuruz i soju.

Tablica 2. Rezultati utjecaja uzgajanih kultura na reakciju i električnu provodljivost tla po mjerenjima

Table 2 Results of the influence of cultivated crops on reaction and electrical conductivity of soil per measuring

\begin{tabular}{|c|c|c|c|c|c|}
\hline Mjerenje/Measuring & $\begin{array}{l}\text { Dubina, cm } \\
\text { Depth, cm }\end{array}$ & $\begin{array}{l}\text { Golo tlo/ } \\
\text { Bare soil }\end{array}$ & $\begin{array}{c}\text { Uljana } \\
\text { repica/ } \\
\text { Oilseed rape }\end{array}$ & $\begin{array}{l}\text { Kukuruz/ } \\
\text { Maize }\end{array}$ & $\begin{array}{c}\text { Soja/ } \\
\text { Soybean }\end{array}$ \\
\hline \multicolumn{6}{|c|}{$\mathrm{pH}, \mathrm{u}$ (in) $\mathrm{H}_{2} \mathrm{O}$} \\
\hline \multirow{2}{*}{ 1. mjerenje/measuring } & $0-30$ & $7,19^{\mathrm{a}}$ & $6,14^{\mathrm{c}}$ & $6,45^{\mathrm{b}}$ & $6,61^{\mathrm{b}}$ \\
\hline & $30-60$ & $7,13^{\mathrm{a}}$ & $6,41^{\mathrm{c}}$ & $6,36^{\mathrm{b}}$ & $6,63^{\mathrm{b}}$ \\
\hline \multirow{2}{*}{ 2. mjerenje/measuring } & $0-30$ & $7,31^{\mathrm{ab}}$ & $6,29^{\mathrm{c}}$ & $7,35^{\mathrm{a}}$ & $7,16^{\mathrm{b}}$ \\
\hline & $30-60$ & $7,30^{\mathrm{a}}$ & $6,45^{\mathrm{b}}$ & $7,31^{\mathrm{a}}$ & $7,16^{\mathrm{a}}$ \\
\hline \multirow{2}{*}{ 3. mjerenje/measuring } & $0-30$ & $7,34^{\mathrm{a}}$ & $6,28^{\mathrm{c}}$ & $7,28^{\mathrm{a}}$ & $6,93^{\mathrm{b}}$ \\
\hline & $30-60$ & $7,35^{\mathrm{a}}$ & $6,41^{\mathrm{c}}$ & $7,24^{\mathrm{a}}$ & $6,98^{\mathrm{b}}$ \\
\hline \multicolumn{6}{|c|}{$\mathrm{pH}, \mathrm{u}$ (in) $1 \mathrm{M} \mathrm{KCl}$} \\
\hline \multirow{2}{*}{ 1. mjerenje/measuring } & $0-30$ & $6,11^{\mathrm{a}}$ & $4,59^{c}$ & $5,29^{b}$ & $5,45^{\mathrm{b}}$ \\
\hline & $30-60$ & $5,89^{\mathrm{a}}$ & $4,81^{\mathrm{c}}$ & $5,15^{\mathrm{b}}$ & $5,41^{\mathrm{b}}$ \\
\hline \multirow{2}{*}{ 2. mjerenje/measuring } & $0-30$ & $6,26^{\mathrm{a}}$ & $4,71^{\mathrm{c}}$ & $6,11^{\mathrm{ab}}$ & $5,97^{\mathrm{b}}$ \\
\hline & $30-60$ & $6,06^{\mathrm{a}}$ & $4,82^{b}$ & $6,08^{a}$ & $5,92^{\mathrm{a}}$ \\
\hline \multirow{2}{*}{ 3. mjerenje/measuring } & $0-30$ & $6,14^{\mathrm{a}}$ & $4,67^{b}$ & $6,20^{\mathrm{a}}$ & $5,93^{\mathrm{a}}$ \\
\hline & $30-60$ & $6,08^{\mathrm{a}}$ & $4,81^{\mathrm{b}}$ & $6,10^{\mathrm{a}}$ & $6,06^{\mathrm{a}}$ \\
\hline \multicolumn{6}{|c|}{ Električna provodljivost, electrical conductivity, (EC), $\mu \mathrm{S}$} \\
\hline \multirow{2}{*}{ 1. mjerenje/measuring } & $0-30$ & $90,46^{\mathrm{a}}$ & $33,06^{b}$ & $77,013^{\mathrm{a}}$ & $61,90^{\mathrm{a}}$ \\
\hline & $30-60$ & $67,76^{\mathrm{a}}$ & $30,65^{b}$ & $68,87^{\mathrm{a}}$ & $60,33^{\mathrm{a}}$ \\
\hline \multirow[b]{2}{*}{ 2. mjerenje/measuring } & $0-30$ & $62,85^{b}$ & $37,80^{\mathrm{c}}$ & $57,60^{b}$ & $76,55^{\mathrm{a}}$ \\
\hline & $30-60$ & $52,85^{\mathrm{b}}$ & $34,80^{\mathrm{c}}$ & $53,26^{\mathrm{b}}$ & $72,30^{\mathrm{a}}$ \\
\hline \multirow{2}{*}{ 3. mjerenje/measuring } & $0-30$ & $72,96^{\mathrm{a}}$ & $39,44^{\mathrm{c}}$ & $58,94^{b}$ & $50,11^{\mathrm{bc}}$ \\
\hline & $30-60$ & $75,34^{\mathrm{a}}$ & $35,93^{\mathrm{c}}$ & $53,84^{b}$ & $60,91^{\mathrm{b}}$ \\
\hline
\end{tabular}

* vrijednosti u redovima označene različitim slovima značajno se razlikuju

* the values in rows marked with different letters differ significantly 
A. Špoljar i sur.: Utjecaj uzgoja kukuruza (Zea mays L.), soje (Glycine max. L.) i uljane repice (Brassica napus L.) na električnu provodljivost i reakciju tla

U tablici 3. i 4. prikazani su rezultati utjecaja uzgajanih kultura na reakciju i električnu provodljivost tla po varijantama (golo tlo i uzgajane kulture) za dubinu od 0 do $30 \mathrm{~cm}$ i od 30 do $60 \mathrm{~cm}$.

Tablica 3. Rezultati utjecaja uzgajanih kultura na reakciju i električnu provodljivost tla po varijantama za dubinu od 0 do $30 \mathrm{~cm}$

Table 3 Results of the influence of cultivated crops on reaction and electrical conductivity of the soil by variants for depths 0 to $30 \mathrm{~cm}$

\begin{tabular}{|l|c|c|c|c|}
\hline Varijanta/Variant & $\begin{array}{c}\text { Dubina, cm } \\
\text { Depth, cm }\end{array}$ & $\begin{array}{c}\mathrm{pH}, \\
\mathrm{u} \text { (in) } \mathrm{H}_{2} \mathrm{O}\end{array}$ & $\begin{array}{c}\mathrm{pH}, \\
\mathrm{u}(\mathrm{in}) \\
1 \mathrm{M} \mathrm{KCl}\end{array}$ & $\begin{array}{c}\text { Električna provodljivost, } \\
\text { Electrical conductivity } \\
\text { (EC), } \mu \mathrm{S}\end{array}$ \\
\hline Golo tlo/Bare soil & $0-30$ & $7,28^{\mathrm{a}}$ & $6,17^{\mathrm{a}}$ & $75,42^{\mathrm{a}}$ \\
\hline $\begin{array}{l}\text { Uljana repica/ } \\
\text { Oilseed rape }\end{array}$ & $0-30$ & $6,23^{\mathrm{c}}$ & $4,66^{\mathrm{c}}$ & $36,77^{\mathrm{b}}$ \\
\hline Kukuruz/Maize & $0-30$ & $7,03^{\mathrm{b}}$ & $5,86^{\mathrm{b}}$ & $64,52^{\mathrm{a}}$ \\
\hline Soja/Soybean & $0-30$ & $6,90^{\mathrm{b}}$ & $5,79^{\mathrm{b}}$ & $64,25^{\mathrm{a}}$ \\
\hline
\end{tabular}

* vrijednosti u stupcima označene različitim slovima značajno se razlikuju

* the values in columns marked with different letters differ significantly

Tablica 4. Rezultati utjecaja uzgajanih kultura na reakciju i električnu provodljivost tla po varijantama za dubinu od $30 \mathrm{do} 60 \mathrm{~cm}$

Table 4 Results of the influence of cultivated crops on reaction and electrical conductivity of the soil by variants for depths 30 to $60 \mathrm{~cm}$

\begin{tabular}{|l|c|c|c|c|}
\hline Varijanta/Variant & $\begin{array}{c}\text { Dubina, cm } \\
\text { Depth, cm }\end{array}$ & $\begin{array}{c}\mathrm{pH}, \\
\mathrm{u} \text { (in) } \mathrm{H}_{2} \mathrm{O}\end{array}$ & $\begin{array}{c}\mathrm{pH}, \\
\mathrm{u} \text { (in) } 1 \mathrm{M} \\
\mathrm{KCl}\end{array}$ & $\begin{array}{c}\text { Električna provodljivost, } \\
\text { Electrical conductivity } \\
\text { (EC), } \mu \mathrm{S}\end{array}$ \\
\hline Golo tlo/Bare soil & $30-60$ & $7,23^{\mathrm{a}}$ & $6,01^{\mathrm{a}}$ & $65,32^{\mathrm{a}}$ \\
\hline $\begin{array}{l}\text { Uljana repica/ } \\
\text { Oilseed rape }\end{array}$ & $30-60$ & $6,42^{\mathrm{c}}$ & $4,81^{\mathrm{c}}$ & $33,79^{\mathrm{b}}$ \\
\hline Kukuruz/Maize & $30-60$ & $6,97^{\mathrm{b}}$ & $5,78^{\mathrm{b}}$ & $58,66^{\mathrm{a}}$ \\
\hline Soja/Soybean & $30-60$ & $6,92^{\mathrm{b}}$ & $5,79^{\mathrm{b}}$ & $64,51^{\mathrm{a}}$ \\
\hline
\end{tabular}

* vrijednosti u stupcima označene različitim slovima značajno se razlikuju

* the values in columns marked with different letters differ significantly

Rezultati utjecaja uzgajanih kultura na reakciju tla po varijantama za dubinu od 0 do $30 \mathrm{~cm}$ i od 30 do $60 \mathrm{~cm}$ ukazuju na statistički opravdano manje vrijednosti $\mathrm{pH}$ mjerenog u vodi i 1 MKCl-u kod svih uzgajanih kultura u odnosu na golo tlo. Između kukuruza i soje opravdanih razlika nije bilo. Pri uzgoju uljane repice utvrđene su statistički opravdano manje vrijednosti električne provodljivosti tla u odnosu na druge istraživane varijante, a između kukuruza i soje također opravdanih razlika nije bilo. 
A. Špoljar i sur.: Utjecaj uzgoja kukuruza (Zea mays L.), soje (Glycine max. L.) i uljane repice (Brassica napus L.) na električnu provodljivost i reakciju tla

Smiley (1974.) navodi kako su pH vrijednosti u području korijenovog sustava pšenice bile manje u odnosu na golo tlo. Autor ističe da se one razlikuju ovisno o sortama i biljnim vrstama te da ovise o vrsti dodanog dušičnog gnojiva. Slične rezultate u šumskim ekosustavima dobivaju Seguin i sur. (2004.). Autori navode kako su pH vrijednosti u području rizosfere uvijek manje u odnosu na prostor izvan nje. Isto tako, utvrđuju veće vrijednosti električne provodljivosti tla u području korijenovog sustava u odnosu na prostor izvan njega. Pandey i sur. (2017.) ističu kako dekstroza dodana u tlo ili ona koju izlučuje korijenov sustav biljaka tvori glukonsku kiselinu, a to dovodi do smanjenja $\mathrm{pH}$ vrijednosti $\mathrm{i}$ elektroprovodljivosti tla. $\mathrm{Na}$ posljedice zakiseljavanja tla u području rizosfere upozorava Rengel (2015.). Autor ističe kako ono uvjetuje porast pristupačnosti i toksičnosti pojedinih mikroelemenata, pa se tako, na primjer, topljivost cinka kod smanjenja $\mathrm{pH}$ vrijednosti za jedan povećava stotinu puta.

Utvrđeno je kako istraživane kulture zakiseljavaju tlo, a pri tome najveći učinak ima uljana repica. Kod nje su na obje dubine tla zabilježene uglavnom najmanje vrijednosti $\mathrm{pH}$ mjerenog u vodi i $1 \mathrm{MKCl}-\mathrm{u}$ te najmanje vrijednosti električne provodljivosti tla. Na kraju istraživanja u odnosu na početak utvrđene su uglavnom veće vrijednosti reakcije i manje vrijednosti električne provodljivosti do $30 \mathrm{~cm}$ dubine tla, što može biti rezultat pretežno vlažnog razdoblja u odnosu na suho razdoblje tijekom vegetacije.

\section{ZAKLJUČAK}

Temeljem izloženoga može se zaključiti sljedeće:

- Utvrđene su manje vrijednosti pH mjerenog u vodi i u 1 MKCl-u kod svih uzgajanih kultura u odnosu na golo tlo (crni ugar). Iz toga proizlazi kako istraživane kulture zakiseljavaju tlo, a pri tome najveći učinak ima uljana repica. Najmanje vrijednosti električne provodljivosti tla također su zabilježene pri uzgoju uljane repice.

- Na kraju istraživanja utvrđene su uglavnom veće vrijednosti reakcije tla i manje vrijednosti električne provodljivosti do $30 \mathrm{~cm}$ dubine tla, što može biti rezultat pretežno vlažnog u odnosu na suho razdoblje tijekom vegetacije. 
A. Špoljar i sur.: Utjecaj uzgoja kukuruza (Zea mays L.), soje (Glycine max. L.) i uljane repice (Brassica napus L.) na električnu provodljivost i reakciju tla

\section{LITERATURA}

1. Abdulaha-Al Baquy, M., Jiu-Yu,L., Chen-Yang X., Mehmood, K., Ren-Kou, X. (2017.): Determination of critical pH concentration of acid Ultisols for wheat and canola crops. Solid Earth, 8: 149-159.

2. Abdulaha-Al Baquy, M., Jin-Yu, L., Jun, J., Khalid, M., Ren-Yong, S., RenKou, X. (2018.): Critical $\mathrm{pH}$ and exchangeable $\mathrm{Al}$ of four acidic soils derived from different parent materials for maize crops. Journal of Soils and Sediments, 18 (4): 1490-1499.

3. Agarwal, N., Singh, A., Kumar, A. (2015.): Salinity effects on growth and productivity of two soybean (Glicine max. L.) genotypes. Indian J. Sci.Res, 6 (2): 59-69.

4. Ashraf, M., McNelly, T. (1990.): Improvement of salt tolerance in maize by selection and breeding. Plant Breeding, 104: 101-107.

5. Azimzadeh, Y., Shirvani, M., Shariatmadari, H. (2015.): Rhizosphere and green manure effects on soil chemical attributes and matal bioavailability as a function of the distance from plant roots in monoand mixed corn and canola cultures. Archives of Agronomy and Soil Science, 62 (8): 1066-1081.

6. Bahizire, F.B. (2007.): Effect of salinity on germination and seedling of canola (Brassica napus L.). Thesis (MScAgric Agronomy - University of Stellenbosch), 64 pages.

7. Bernstein, L., G. Ogata, G. (1966.): Effects of salinity on nodulation, nitrogen fixation, and growth of soybeans and alfalfa. Agronomy Journal, 58:201-203.

8. Fox, R.H. (1979.): Soil pH, aluminum saturation, and corn grain yield. Soil Science, 127 (6): 330-334.

9. Franzen, D.E. (2007.): Managing saline soils in North Dakota. NDSU Extension Service North Dakota University, Fargo, 11 pages.

10. Hassan, N.A.K., Drew, J.V, Knudsen, D., Olson, R.A. (1970.): Influence of soil salinity on production of dry matter and uptake and distribution of nutrients in barley and corn: II. Corn (Zea mays). Agronomy Journal, 62:46-48.

11. Kamkar, B., Ali Dorri, M., Jamie, A. (2014.): Assessment of land suitability and possibility and performance of a canola (Brassica napus L.) - soybean (Glycine $\max L)$ totation in four basins of Golestan province, Iran. The Egyptian Journal of Remote Sensing and Space Science, 17 (1): 95-104.

12. Liang, J., Fang, H., Hao, G. (2016): Effect of Plant Roots on Soil Nutrient Distributions in Shanghai Urban Landscapes. American Journal of Plant Sciences, Version On-line:

http://creativecommons.org/licences/by/4.0/, (2019/05/09 at 08:51:39). 
A. Špoljar i sur.: Utjecaj uzgoja kukuruza (Zea mays L.), soje (Glycine max. L.) i uljane repice (Brassica napus L.) na električnu provodljivost i reakciju tla

13. Nawaz, M.F., Bourrie, G., Gul, S., Trolard, F.,Ahmad, I., Tanvir, M.A., Mouret, J.C. (2012): Impact of rice plant roots on the variation in electrophysico-chemical properties of soil waters. Pakistan Journal of Botany, 44(6): 1891-1896.

14. Pandey, C.B., Kumar, P., Chaudhari, S.K. (2017.): Root exudates reduce electrical conductyvity and water potential of rhizospheres and facilitate non-halophytes to survive in dry land saline soils. Tropical Ecology, 58(4): 705-716.

15. Pernar, N., Bakšić, D., Perković, I. (2013.): Terenska i laboratorijska istraživanja tla. Sveučilište u Zagrebu, udžbenik, 192. str.

16. Rengel, Z. (2002.): Role of $\mathrm{pH}$ in availability of ions in soil. In: Z. Rengel (ed.) Handbook of Plant Growth. $\mathrm{pH}$ as a Master Variable in Plant Growth. Marcel Dekker, New York, pp: 323-350.

17. Rengel, Z. (2015.): Availability of Mn, Zn and Fe in the rhizosphere. Journal of soil science and plant nutrition. Journal of Soil Science and Plant Nutrtion, 15(2): 397-409.

18. Seguin, V., Gagnon, C., Courchesne, F. (2004.): Changes in water extractable metals, $\mathrm{pH}$ and organic carbon concentzrations at the soil-root interface of forested. Plant and Soil, 260 (1-2): 1-17.

19. Smiley, R.W. (1974.): Rizosphere $\mathrm{pH}$ as influenced by plants, soils, and nitrogen fertilizers. Soil Science Society of America Journal Abstract, 38 (5): 795-799.

20. Špoljar, A. (2008.): Utjecaj gnojidbe na fizikalno-kemijske značajke tla. Disertacija, Agronomski fakultet Sveučilišta u Zagrebu, 148. str.

21. Vukadinović, V. (2011.): Ishrana bilja. Poljoprivredni fakultet, Sveučilište J.J. Strossmayera u Osijeku, udžbenik, 442 str.

22. Williams, K., Stevenson, W., Vaughan, J. (2005.): Application of Paper Mill Residual to Potato/Corn/Soybean. UWEX Langlade Co. and Dept. of Plant Pathology, Univ. of Wisconsin-Madison, 9 pages.

$* * *$ https://extension.usu.edu/publications/publication SO-03.pdf.

*** Statistica 12.1. (StafSoft, Inc. 2012). 
A. Špoljar i sur.: Utjecaj uzgoja kukuruza (Zea mays L.), soje (Glycine max. L.) i uljane repice (Brassica napus L.) na električnu provodljivost i reakciju tla

Adresa autora - autor's address:

dr.sc. Andrija Špoljar, prof. v. š.

Primljeno - Received:

dr. sc. Ivka Kvaternjak, prof. v. š.

10.05.2019.

Drago Žibrin, dipl. ing. agr.

Mužić Mirjana, bacc. ing. agr.

Visoko gospodarsko učilište u Križevcima

M. Demerca 1, Križevci, Hrvatska 
A. Špoljar i sur.: Utjecaj uzgoja kukuruza (Zea mays L.), soje (Glycine max. L.) i uljane repice (Brassica napus L.) na električnu provodljivost i reakciju tla 